\title{
Investigating the Effect of Auto-Focus and Auto-Threshold Algorithms in Advanced Nodularity Analysis of Austempered Ductile Iron Castings
}

\author{
B. Çetin ${ }^{a, *}$, H. Kurtuldu ${ }^{b}$, G. Durkaya ${ }^{c}$ And K. Davut ${ }^{c}$ \\ ${ }^{a}$ FNSS Defense Systems Co. Inc., Engineering and Research Department, Ankara, Turkey \\ ${ }^{b}$ Baskent University, Department of Biomedical Engineering, Ankara, Turkey \\ ${ }^{c}$ Atılım University, Department of Metallurgical and Materials Engineering, Ankara, Turkey
}

\begin{abstract}
Austempered ductile iron castings have a wide range of application fields including defense and heavy-duty industries due to their promising mechanical properties. Austempered ductile iron castings could provide excellent combination of high strength, toughness, and wear resistance at the same time. Unlike other spheroidal ductile cast irons, austempered ductile iron castings need to be processed by a special austempering heat treatment which enables the verification of the conformity of the nodularity level after the casting operations. Previous studies have shown that wide area mappings for determining nodularity are crucial to eliminate the representativeness problems. In this sense, some precautions should be taken for the accuracy of results in large scale nodularity examination In this study, the effect of auto-thresholding and auto-focusing algorithms on the advanced nodularity analysis is investigated. The results suggest that auto-thresholding and auto-focusing methods have significant contributions for determining average nodularity levels and average graphite sizes.
\end{abstract}

DOI: 10.12693/APhysPolA.135.762

PACS/topics: auto-threshold, auto-focus, image analysis, nodularity analysis, austempered ductile iron castings

\section{Introduction}

Due to strict design requirements, there is a continuous demand for improving new alternative materials which exhibit promising mechanical properties. Particularly, simultaneous results in both high strength and durability play important roles in the defense industry where the service conditions are severely compelling. Austempered ductile iron (ADI) is a specific type of spheroidal graphite cast iron (SGCI) grade with attractive mechanical properties such as higher tensile, fatigue strength, toughness and relatively good ductility which make it superior to the other grades of ductile irons [1-3]. Furthermore, ADI has a higher specific strength value due to its lower density compared to steel $[4,5]$. Therefore, it can also serve as a light-weight material compared to forged steel or steel castings.

ADI is obtained after a specific heat treatment of SGCI which is known as austempering operation. Austempering process includes two steps: austenization at temperatures around $850^{\circ} \mathrm{C}$ to $950^{\circ} \mathrm{C}$, followed by rapid cooling to an isothermal transformation temperature range $\left(220^{\circ} \mathrm{C}-420^{\circ} \mathrm{C}\right)$ for 1 to $4 \mathrm{~h}$ before coming to room temperature $[6,7]$. A specific microstructure called ausferrite occurs as a result of this austempering heat treatment. Ausferrite is basically composed of acicular ferrite and carbon enriched austenite phases. The typical microstructure of an ADI material is illustrated in Fig. 1a and b.

*corresponding author; e-mail: cetin.baris@fnss.com.tr
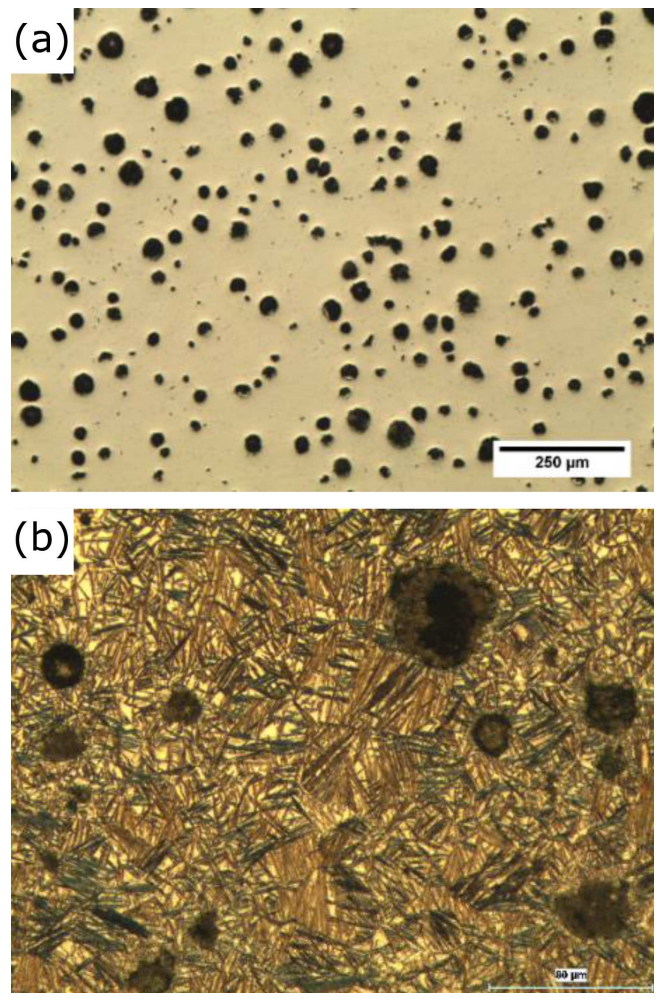

Fig. 1. Optical micrograph of (a) as-polished ADI sample $(50 \times)$, (b) an etched sample $(200 \times)$.

The matrix microstructure of ADI as well as the graphite morphology should be proper for the desired mechanical properties. The insufficient nodularity (circularity) of graphite particles results in lower strength 
and ductility values. For instance, the ISO-17804 standard recommends at least $85 \%$ nodularity to achieve the desired mechanical properties of ADI. The correlation between the strength of SGCI and the graphite nodularity is also a well-known fact in metallurgical engineering $[8,9]$. Considering costly and time-consuming (1-4 h) austempering operations, determining the nodular properties of ADI materials beforehand is essential. Previous studies have shown that the investigation over large surfaces is necessary in order to eliminate representativeness problems [7]. Topological (e.g., height variations on the surface) and optical (e.g., brightness differences among images) effects need to be minimized in the nodularity analysis performed by wide area scanning. In this study, we propose a novel method to investigate the nodularity of ADI materials in large surface areas. Auto-focus and auto-thresholding algorithms are studied and compared with the conventional techniques (manual thresholding and no auto-focusing) already used in industrial applications for nodularity analysis.

\section{Experimental procedure}

As delineated in Fig. 2a and b, the surface of an ADI sample is raster scanned using a metallurgical microscope (AUTOMET PSARON HTI) at 196 points corresponding to a total scan area of nearly $223 \mathrm{~mm}^{2}$. Optical images for nodularity analysis are acquired at each scan point.

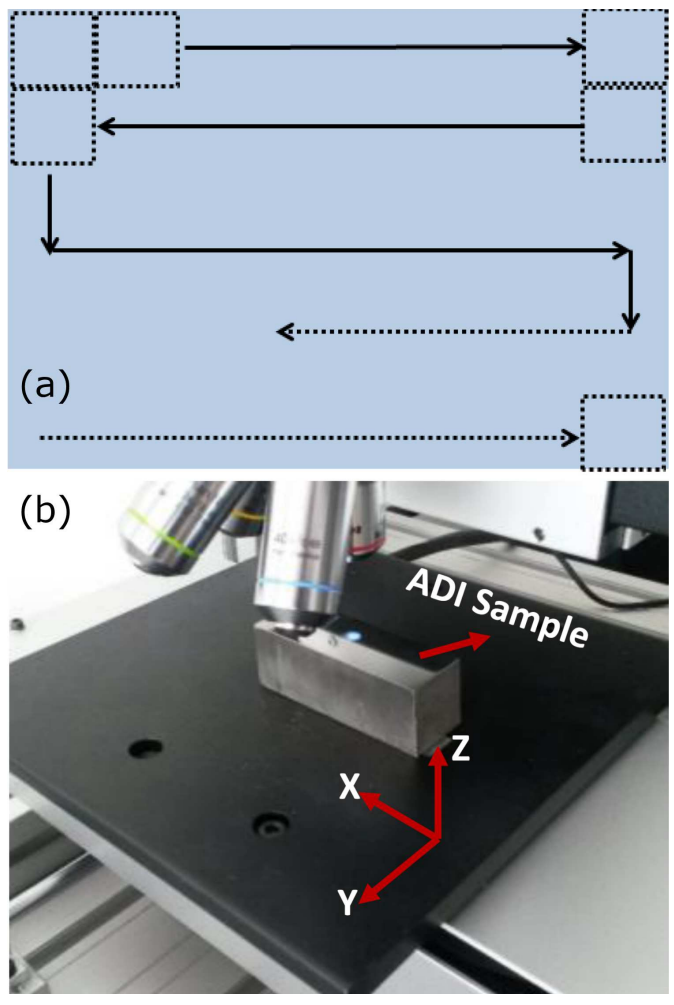

Fig. 2. (a) Raster scanning methodology of the ADI sample, (b) AUTOMET optical microscopy system.
Each image is processed and analyzed according to the ASTM E2567 standard, where graphite particles are classified based on intensity (image contrast), particle size (maximum Feret's diameter: MFD), and shape factor (SF). Only the graphites which have met the minimum cross-sectional area requirement (MFD $\geq 10 \mu \mathrm{m})$ are accepted as graphite particles. Furthermore, the particles which meet the nodularity criteria (with $\mathrm{SF} \geq 0.6$ ) are considered as nodular graphites. Each image in the scan is used to characterize the spatial distribution of nodular properties. Table I summarizes the experimental parameters in the scanning analysis.

TABLE I

Experimental parameters in scanning nodular analysis

\begin{tabular}{l|c}
\hline \hline Area of a single matrix field & $\begin{array}{c}1138368 \mu \mathrm{m}^{2} \\
\left(\approx 1.14 \mathrm{~mm}^{2}\right)\end{array}$ \\
\hline Number of matrix fields analyzed & 196 \\
\hline Total matrix area analyzed & $223.44 \mathrm{~mm}^{2}$ \\
\hline Pixel calibration factor & 0.85
\end{tabular}

The motorized stages in the microscopy system enable the raster scan to be made automatically in pre-defined areas. Moreover, the motorized $Z$-axis of the optical system provides an automatic control of the best focusing plane. At each image position, the system searches for the best focus by changing the $Z$ position of the objective lens. The auto-thresholding is performed by a specifically designed software for the images. The Otsu method is used for auto-thresholding of the images to distinguish the graphite particles from the matrix structure (background). This thresholding technique is a clusteringbased method employed to minimize the intra-class variance between black and white pixels $[10,11]$. In this study, the nodularity on the 196 surface points of the ADI sample is analyzed by four different methods: (i) with manual thresholding and without auto-focusing, (ii) with manual thresholding and auto-focusing, (iii) with autothresholding and without auto-focusing, and (iv) with auto-thresholding and auto-focusing.

\section{Results and discussion}

The average nodularity by area and average graphite size for 196 surface points of the ADI sample, calculated with manual thresholding and without performing autofocusing, are shown in Figs. 3 and 4, respectively. It is seen that both values are not constant and fluctuate over the surface. For a visualization of the spatial dependence of the nodular properties, the average nodularity and the graphite size are color-coded from blue to red on the sample surface. Figure 5 demonstrates the average nodularity computed by four different methods in a $7 \times 28$ field grid corresponding to a physical area of $223.44 \mathrm{~mm}^{2}$. Similarly, Fig. 6 illustrates how the average graphite size varies over the surface. The application of both the autofocusing and auto-thresholding algorithms results in approximately $5 \%$ change in the nodularity analysis. 


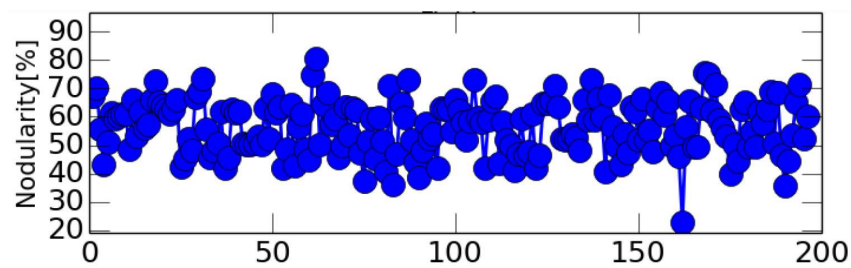

Fig. 3. Average nodularity for 196 surface point with manual thresholding and without auto-focusing.

(a) Manual Thresholding - No auto-ocusing

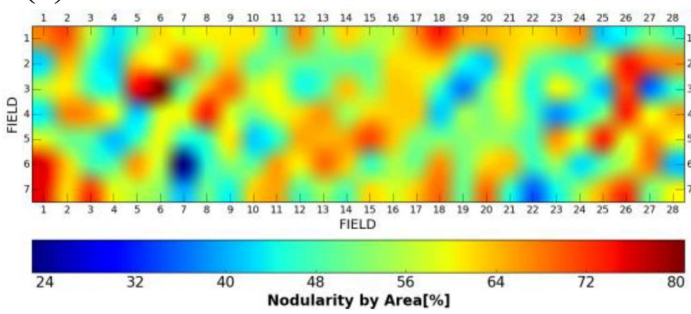

MEAN: 56.42 STD: 9.47 MIN: 22.81 MAX: 80.70

(c) Manual Thresholding - Auto-focusing

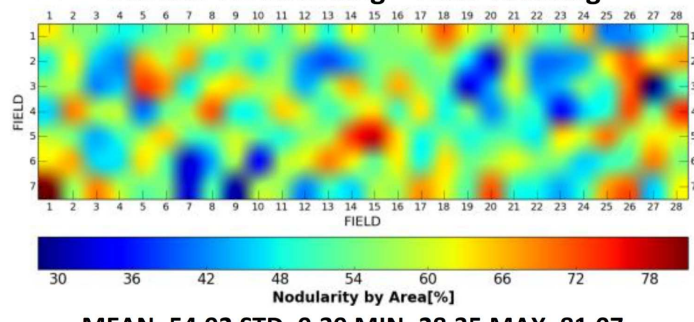

MEAN: 54.92 STD: 9.39 MIN: 28.35 MAX: 81.07

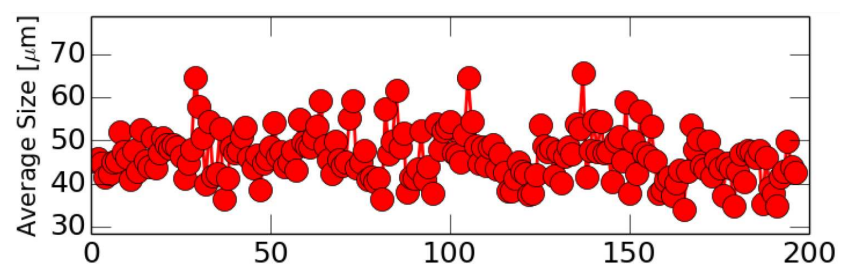

Fig. 4. Average graphite size for 196 surface points with manual thresholding and without auto-focusing.

(b) Auto-thresholding - No auto-focusing

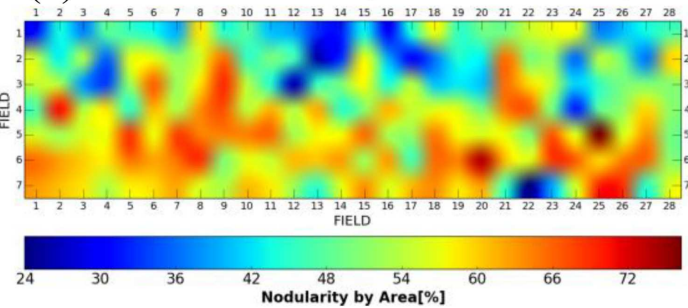

MEAN: 53.39 STD: 10.01 MIN: 23.93 MAX: 76.24

(d) Auto-thresholding - Auto-focusing

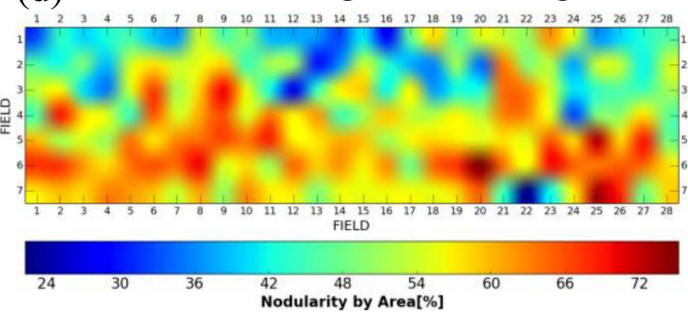

MEAN: 53.54 STD: 9.85 MIN: 22.27 MAX: 75.16

Fig. 5. Colormap representation of nodularity by area in $223.44 \mathrm{~mm}^{2}$ surface area $(7 \times 28=196$ fields $)$ with mean, standard deviation (STD), minimum (MIN) and maximum values (MAX) for four different analysis methods: (a) manual thresholding with no auto-focusing, (b) auto-thresholding with no auto-focusing, (c) manual thresholding with autofocusing and (d) auto-thresholding with auto-focusing.

(a) Manual Thresholding - No auto-focusing

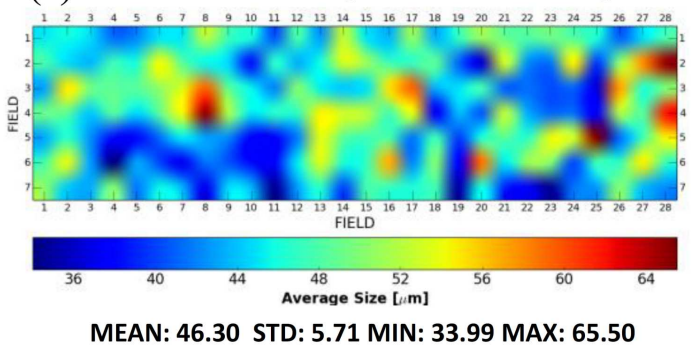

(c) Manual Thresholding - Auto-focusing

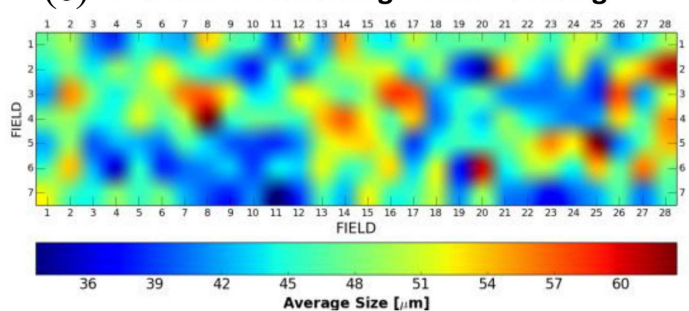

MEAN: 46.47 STD: 5.40 MIN: 33.63 MAX: 62.51 (b) Auto-thresholding - No auto-focusing

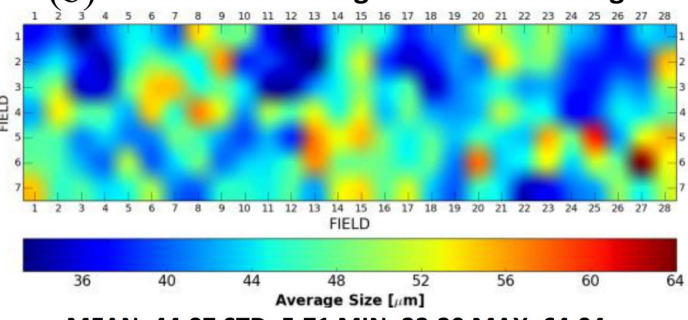

MEAN: 44.97 STD: 5.71 MIN: 33.20 MAX: 64.04

(d) Auto-thresholding - Auto-focusing

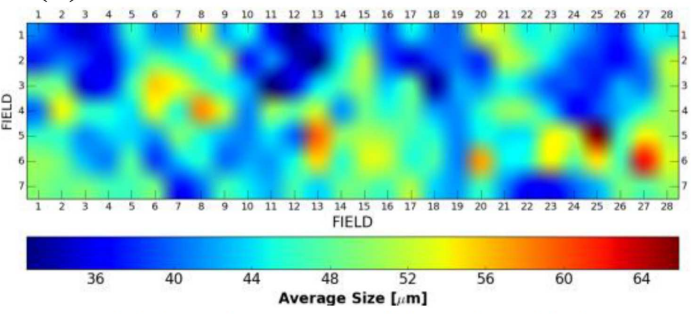

MEAN: 44.80 STD: 5.64 MIN: 32.43 MAX: 65.89

Fig. 6. As in Fig. 5, but for representation of average graphite size in $223.44 \mathrm{~mm}^{2}$ surface area. 
Since the nodular properties have a high spatial dependence, the analysis at only a few points of the surface could lead to improper metallurgical interpretations. Furthermore, the metallographic samples may not be as smooth as expected even though they are prepared through standardized metallurgical procedures (grinding and polishing). Therefore, implementing auto-focusing mechanisms in metallurgical inspection systems could increase the measurement accuracy. The manually set threshold value to separate the graphites from the background depends on the user's experience. Hence, by applying the automatic thresholding, the consistency between measurements performed by different users can be increased.

\section{Conclusion}

In this study, we investigate the nodularity properties of an ADI material with an area of $223 \mathrm{~mm}^{2}$ and propose that raster scanning of the surface with the implementation of auto-focusing and auto-thresholding methods is essential to obtain a statistically significant analysis of nodularity. We expect these methods to have a higher effect on the measurement of materials with much larger surface area.

\section{References}

[1] Cast Metals Development Ltd, Alvechurch, Birmingham, Mater. Des. 13, 285 (1992).

[2] B. Çetin, H. Meço, E. Arslan, K. Davut, M.C. Uzun, Hittite J. Sci. Eng. 3, 29 (2016).

[3] J. Zimba, D.J. Simbi, E. Navara, Cement Concr. Composit. 25, 643 (2003).

[4] J.F. Janowak, P.A. Norton, AFS Trans. 88, 123 (1985).

[5] S.K. Putatunda, Mater. Sci. Eng. A 315, 70 (2011).

[6] L.C. Chang, Metall. Mater. Trans. A 34, 211 (2003).

[7] B. Cetin, H. Kurtuldu, G. Durkaya, K. Davut, Microsc. Microanal. 23, 232 (2017).

[8] Ductile Iron Society Research Project No. 37.

[9] A.I. Alghonamy, M. Ramadan, N. Fathy, K.M. Hafez, A.A. Elwakil, Int. J. Civil Environ. Eng. 10, 1 (2010)

[10] N. Otsu, EEE Trans. Syst. Man Cybernet. 9, 62 (1989).

[11] X. Xu, S. Xu, L. Jin, E. Song, Pattern Recognit. Lett. 32, 956 (2011). 